\title{
Effect of Suckling on Embryo Production by Repeated Ovum Pick-Up Before and After Timed Artificial Insemination in Early Postpartum Japanese Black Cows
}

\author{
Toh-Ichi HIRATA ${ }^{1)}$, Mai SATO ${ }^{1)}$, Shu-Ichi SASAKI ${ }^{1)}$, Osamu SASAKI ${ }^{1)}$ and Takeshi OSAWA ${ }^{1)}$ \\ ${ }^{1)}$ Department of Veterinary Medicine, Faculty of Agriculture, Iwate University, Morioka 020-8550, Japan
}

\begin{abstract}
We investigated whether suckling would affect embryo production of cows bred by timed artificial insemination (TAI) following an ovulation synchronization protocol combined with ovum pick-up and progesterone releasing intravaginal device (OPU-PRID-TAI protocol). The number of oocytes and transferable embryos collected by repeated OPU, performed before and after TAI, were recorded. A total of 14 Japanese Black cows were divided into weaned $(n=7)$ and suckled groups $(n=7)$. All 14 cows were treated with OPU on day 0 (the first day of treatment) and then with a PRID for 9 days. Prostaglandin $F_{2 \alpha}$ analog was administered on day 7, GnRH analog was administered on day 10 ( $36 \mathrm{~h}$ after removal of the PRID) and TAI was performed $12 \mathrm{~h}$ later. Ovulation was confirmed by palpation per rectum the following day. After TAI, additional OPU sessions were performed on days 18, 25 and 32 . The synchronized ovulation rates of the weaned and suckled groups were 100 and $85.7 \%$, and the conception rates were 71.4 and $42.9 \%$, respectively. Immature oocytes were fertilized and cultured in vitro. The numbers of oocytes collected and blastocysts generated were similar between the individual OPU sessions in both groups. However, the total numbers of oocytes collected, cultured oocytes, cleavage embryos and blastocysts as well as the proportions of cleavage embryos and blastocysts to cultured oocytes were all significantly $(\mathrm{P}<0.05)$ greater in the weaned group compared with the suckled group. These results suggest that the OPU-PRID-TAI protocol has the potential to produce a significant number of good-quality embryos in vitro after repeated OPU in early postpartum weaned Japanese Black cows. To collect more oocytes and produce more embryos, we suggest that calves be removed from cows scheduled for treatment using this protocol.
\end{abstract}

Key words: Cow, Early postpartum, Japanese black, Ovum pick-up (OPU), Suckling, Timed artificial insemination (TAI)

(J. Reprod. Dev. 54: 346-351, 2008)

I $\mathrm{t}$ is economically advantageous for beef cattle producers to have cows in estrus within 60 days postpartum and pregnant within 80 days postpartum and to produce a calf each year. An increase in days open results in a significant economic loss, particularly in the case of Japanese Black cows whose calves have a high market value because of the marbled meat they produce. Various estrus and ovulation synchronization programs have been applied to early postpartum beef cows to achieve maximum reproductive ability [1-3]. Use of intravaginal progesterone devices in these programs has been effective in animals with silent heat or anestrus [4].

Transvaginal ovum pick-up (OPU), a technique for collecting oocytes from live donor cows using ultrasound-guided transvaginal oocyte aspiration, and in vitro embryo production (IVP) have become important methods for making the most of the genetic traits of superior donors in the beef industry [5-8]. In addition, OPU is applicable to animals in various reproductive states, including the cyclic, non-cyclic and early pregnancy states [9-13].

We previously reported that it is possible to attain high conception and production rates for embryos by IVP in Japanese Black cows within 60 days postpartum, regardless of resumption of ova-

Accepted for publication: June 13, 2008

Published online in J-STAGE: July 7, 2008

Correspondence: T. Osawa (e-mail: osawa@iwate-u.ac.jp) rian activity at the onset of treatment, by applying an ovulation synchronization protocol in combination with the OPU technique on day 0 and placement of a progesterone releasing intravaginal device (PRID) from day 0 for 7 days [14]. However, suckling has been suggested to delay postpartum resumption of ovarian function in beef cows because the suckling stimulus exerts negative feedback on the hypothalamus [1]. It remains unknown how the negative impact of suckling influences the number and quality of oocytes collected by OPU.

The objectives of this study were to clarify whether suckling affects the embryo production of cows bred by timed artificial insemination following an ovulation synchronization protocol combined with OPU and PRID (OPU-PRID-TAI protocol). The number of oocytes collected by repeated OPU and transferable embryos generated by IVP, performed once before TAI and three times after TAI, were recorded.

\section{Materials and Methods}

\section{Animals}

A total of 14 Japanese Black cows kept at Omyojin Experimental Station, Iwate University, were used and divided into the following two groups: a weaned group (calves weaned at 7 days postpartum; $\mathrm{n}=7$ ) and suckled group (calves allowed to suckle their dams freely until the end of the experiment; $n=7$ ). Each animal in 
the groups was healthy and housed in an individual pen under identical conditions, and was fed $2 \mathrm{~kg}$ daily of a mixed feed (at least $16 \% \mathrm{CP}$, at least $74 \% \mathrm{TDN}$ ) and orchard silage (77.8\% DM, 14.0\% CP, 58\%TDN, $24.3 \% \mathrm{CF}$ ) ad libitum to meet the nutrient requirements of the Japanese Feeding Standard for Beef Cattle (Agriculture, Forestry and Fisheries Research Council Secretariat, 2000). The ages, numbers of parities, days postpartum and body weights (mean $\pm \mathrm{SD}$ ) of the weaned and suckled groups at the onset of the experiment were $37.0 \pm 14.2$ and $47.7 \pm 22.6$ months old, 1.7 \pm 1.1 and $2.4 \pm 1.6$ parities, $28.3 \pm 4.8$ and $29.7 \pm 5.0$ days and $356.3 \pm 36.5$ and $371.9 \pm 60.2 \mathrm{~kg}$, respectively, and were not significantly different between the two groups. All procedures were carried out in accordance with a protocol approved by the Animal Care and Use Committee of Iwate University.

\section{Timed AI protocol}

The 14 cows were treated with OPU on day 0 (the first day of treatment) and were fitted with a PRID (containing $1.55 \mathrm{~g}$ of progesterone and an estradiol benzoate capsule containing $10 \mathrm{mg}$ of estradiol benzoate; Aska Pharmaceutical, Tokyo, Japan) immediately after OPU. The device was left in the animals for 9 days, and $500 \mu \mathrm{g}$ of cloprostenol, a prostaglandin $\mathrm{F}_{2 \alpha}$ analog (Estrumate; Nagase Medicals, Itami, Japan), was administered intramuscularly on day 7, two days before removal of the PRID. Fertirelin acetate (100 $\mu \mathrm{g})$, a GnRH analog (Conceral; Nagase Medicals), was administered by intramuscular injection on day 10 (36 h after removal of the PRID), TAI was conducted $12 \mathrm{~h}$ later (day 11). Ovulation was confirmed by palpation per rectum the following day. After TAI, OPU was performed three times with an interval of 7 days (on days 18, 25 and 32).

Palpation per rectum was performed to monitor ovarian status. Blood samples were taken from the jugular vein into heparinized vacuum tubes on days $0,7,9,10,11,12,18,25$ and 32 . Plasma was separated by centrifugation at $700 \times g$ for $15 \mathrm{~min}$. The plasma samples were then stored at $-20 \mathrm{C}$ until hormone assays were performed. Pregnancy diagnosis was made approximately 60 days after TAI by rectal palpation.

\section{Hormone assays}

Plasma concentrations of progesterone and estradiol-17 $\beta$ were determined by radioimmunoassay [15]. Ovine antisera raised against progesterone, GDN\#337, and against estradiol-17 $\beta$, GDN\#244, were provided by Dr. Niswender GD (Colorado State University, Fort Collins, CO, USA). The sensitivity and intra- and interassay coefficients of variation were $0.04 \mathrm{ng} / \mathrm{ml}, 9.3 \%$ and $7.6 \%$ for progesterone and $0.2 \mathrm{pg} / \mathrm{ml}, 7.0 \%$ and $12.7 \%$ for estradiol- $17 \beta$, respectively.

\section{Ovum pick-up}

All cows were restrained in standing stocks, sedated with 0.04 mg/kg BW xylazine (Celactal; Bayer Medical, Tokyo, Japan) administered intramuscularly and treated with antispasmodic prifinium bromide (75 mg/head intravenously; Taiyo Yakuhin, Nagoya, Japan) in order to decrease rectal peristalsis. Immature oocytes of follicles $3 \mathrm{~mm}$ or greater in diameter were harvested from the ovaries using an ultrasound-guided transvaginal aspiration system (SSD-900 ultrasonograph, UST-M15-21079 probe; Aloka, Tokyo, Japan) equipped with disposable 17-G single-lumen sterile needles (COVA needle; Misawa Medical, Tokyo, Japan) using 70 to $80 \mathrm{mmHg}$ of suction pressure. The immature oocytes were collected in 1\% heparin (Novoheparin; Novo Industry, Bajsvaeld, Denmark) containing modified phosphate-buffered saline (m-PBS; Embryotec, Nippon-Zenyaku Kougyo, Kouriyama, Japan) and examined under a microscope. Collected oocytes without cumulus cells, those with expanded cumulus cells and those $100 \mu \mathrm{m}$ or smaller in diameter were excluded, and the rest of the collected oocytes were cultured (cultured oocytes).

\section{In vitro embryo production}

In vitro embryo production (IVP) was performed according to procedures described previously [16]. Briefly, the oocytes were cultured in drops of $200 \mu \mathrm{l}$ in vitro maturation medium (IVMD 101; Research Institute for the Functional Peptides, Yamagata, Japan) covered with $100 \mu \mathrm{l}$ mineral oil for $20 \mathrm{~h}$ at $38.5 \mathrm{C}$ in $5 \%$ $\mathrm{CO}_{2}$ in a six-well culture plate (Repro C-1 plate; Research Institute for the Functional Peptides). Frozen semen supplied by Livestock Improvement Association of Japan (Tokyo) was thawed at $37 \mathrm{C}$ and washed twice, first in phosphate buffered solution and then in fertilization medium (IVF 100; Research Institute for the Functional Peptides), by centrifugation at $700 \times g$ for $5 \mathrm{~min}$. The final sperm pellet was resuspended in the same medium to adjust the concentration to $1.0 \times 10^{7} \mathrm{spermatozoa} / \mathrm{ml}$. For IVF, a $25 \mu \mathrm{l}$ aliquot of spermatozoa suspension was combined with a $25 \mu$ droplet of IVF 100 medium for $8 \mathrm{~h}$. After in vitro fertilization, the presumptive zygotes were transferred to $200 \mu$ of IVMD 101 for $16 \mathrm{~h}$, denuded, transferred to $200 \mu \mathrm{l}$ culture medium (IVD-101; Research Institute for the Functional Peptides) and cultured at 38.5 C in 5\% $\mathrm{O}_{2}$ and $5 \% \mathrm{CO}_{2}$ in $\mathrm{N}_{2}$ for 8 days. The percentage of cleavage embryos was assessed 2 days after insemination, and blastocyst formation was assessed after 7 to 9 days of culture.

\section{Statistical analyses}

The ovulation synchronization and conception rates of the two groups were compared using Fisher's exact probability test. Twoway repeated measures ANOVA was used to analyze time-course differences in the progesterone and estradiol- $17 \beta$ concentrations and the numbers of oocytes collected, cleavage embryos and blastocysts among the four OPU sessions between the weaned and suckled groups and between the subsequent pregnant and non-pregnant groups. Where appropriate, differences in hormone measurements and in OPU outcome were compared between the two groups by unpaired $t$-test. Comparisons of the proportions of cleavage oocytes and blastocysts to cultured oocytes were made between the weaned and suckled groups and between the pregnant and non-pregnant groups using the $\chi^{2}$ test. Values are expressed as means \pm SEM. Differences were considered to be significant at $\mathrm{P}<0.05$. These analyses were performed using the StatView 4.0 software (Abacus Concepts, Berkeley, CA, USA). 
Table 1. Comparison of the ovum pick-up (OPU) results of the four sessions at different times before and after the OPUPRID-Timed AI (TAI) protocol between the weaned and suckled Japanese Black cows

\begin{tabular}{|c|c|c|}
\hline & Weaned $(n=7)$ & Suckled $(\mathrm{n}=7)$ \\
\hline Total number of OPU sessions & 28 & 28 \\
\hline Oocytes collected from the 4 OPU sessions & $\begin{array}{c}494 \\
(17.6 \pm 11.1)^{\mathrm{a} * *}\end{array}$ & $\begin{array}{c}301 \\
(10.8 \pm 6.7)^{* *}\end{array}$ \\
\hline Session 1 (Day $0^{\mathrm{b}}$ ) & $\begin{array}{c}142 \\
(20.3 \pm 12.8)\end{array}$ & $\begin{array}{c}81 \\
(11.6 \pm 5.5)\end{array}$ \\
\hline Session 2 (7 days after TAI) & $\begin{array}{c}88 \\
(12.6 \pm 9.0)\end{array}$ & $\begin{array}{c}83 \\
(11.9 \pm 4.2)\end{array}$ \\
\hline Session 3 (14 days after TAI) & $\begin{array}{c}139 \\
(19.9 \pm 13.7)\end{array}$ & $\begin{array}{c}69 \\
(9.9 \pm 10.1)\end{array}$ \\
\hline Session 4 (21 days after TAI) & $\begin{array}{c}125 \\
(17.9 \pm 8.6)\end{array}$ & $\begin{array}{c}68 \\
(9.7 \pm 7.0)\end{array}$ \\
\hline Cultured oocytes ${ }^{c}$ & $\begin{array}{c}441 \\
(15.8 \pm 9.6)^{*}\end{array}$ & $\begin{array}{c}288 \\
(10.3 \pm 5.6)^{*}\end{array}$ \\
\hline Cleavage embryos & $\begin{array}{c}241 \\
(8.6 \pm 7.2)^{*}\end{array}$ & $\begin{array}{c}132 \\
(4.7 \pm 4.0)^{*}\end{array}$ \\
\hline Proportion of cleavage embryos to cultured oocytes (\%) & $54.6^{*}$ & $45.8^{*}$ \\
\hline Blastocysts generated (day 7 from IVF) & $\begin{array}{c}70 \\
(2.5 \pm 3.4)^{*}\end{array}$ & $\begin{array}{c}25 \\
(0.9 \pm 1.9)^{*}\end{array}$ \\
\hline Proportion of blastocysts (day 7) to cultured oocytes (\%) & $15.9 * *$ & $8.7^{* *}$ \\
\hline Blastocysts generated (days 7-9 from IVF) & $\begin{array}{c}99 \\
(3.5 \pm 4.0)^{*}\end{array}$ & $\begin{array}{c}36 \\
(1.3 \pm 1.8)^{*}\end{array}$ \\
\hline Proportion of blastocysts (day 7-9) to cultured oocytes (\%) & $22.4^{* *}$ & $13.5^{* *}$ \\
\hline Session $1^{\mathrm{d}}$ (Day 0 ) & $\begin{array}{c}19 \\
(2.7 \pm 3.5)\end{array}$ & $\begin{array}{c}11 \\
(1.6 \pm 2.1)\end{array}$ \\
\hline Session 2 ( 7 days after TAI) & $\begin{array}{c}15 \\
(2.1 \pm 2.4)\end{array}$ & $\begin{array}{c}4 \\
(0.6 \pm 0.8)\end{array}$ \\
\hline Session 3 (14 days after TAI) & $\begin{array}{c}38 \\
(5.4 \pm 5.8)\end{array}$ & $\begin{array}{c}10 \\
(1.4 \pm 1.8)\end{array}$ \\
\hline Session 4 (21 days after TAI) & $\begin{array}{c}27 \\
(3.9 \pm 3.5)\end{array}$ & $\begin{array}{c}11 \\
(1.6 \pm 2.6)\end{array}$ \\
\hline
\end{tabular}

* and **: Significant differences between the two groups within the same row $\left(\mathrm{P}<0.05\right.$ and 0.01 , respectively). ${ }^{\text {a }}$ The average

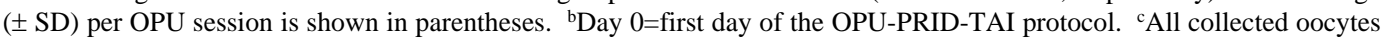
but those without cumulus cells, those with expanded cumulus cells and those $100 \mathrm{~mm}$ or smaller in diameter. ${ }^{\mathrm{d}}$ Number of blastocysts generated (days 7-9 from IVF) from session 1.

\section{Results}

\section{Ovarian dynamics and conception rate}

Thirteen (92.9\%) of the 14 animals had synchronized ovulation after GnRH injection and subsequently had a corpus luteum (CL). No significant difference was found in the ovulation synchronization rates between the weaned $(100 \% ; 7 / 7)$ and suckled $(85.7 \%, 6 / 7)$ groups.

Eight of the 14 animals (57.1\%) conceived with the OPU-PRIDTAI protocol. No significant difference was found in the conception rates between the weaned (71.4\%) and suckled (42.9\%) groups.

\section{OPU outcome}

The numbers of oocytes collected and blastocysts generated were similar among the four OPU sessions in the weaned and suckled groups (Table 1).

The total numbers of oocytes collected $(\mathrm{P}<0.01)$, cultured oocytes $(\mathrm{P}<0.05)$, total numbers and proportions of cleavage embryos to cultured oocytes $(\mathrm{P}<0.05)$, numbers of blastocysts generated on day 7 from IVF $(P<0.05)$, proportions of blastocysts on day 7 to cultured oocytes $(\mathrm{P}<0.01)$, total numbers of blastocysts on days 7-9 $(\mathrm{P}<0.05)$ and proportions of blastocysts on days 7-9 $(\mathrm{P}<0.01)$ of the four OPU sessions were significantly higher in the weaned group compared with the suckled group.

There was no significant difference in OPU outcome between subsequent pregnant and non-pregnant groups.

\section{Hormonal profiles}

The profiles of the progesterone and estradiol- $17 \beta$ concentrations in the weaned and suckled groups are summarized in Fig. 1. Two-way repeated measures ANOVA analysis revealed a significant difference in the progesterone profile between the weaned and suckled groups $(\mathrm{P}=0.03)$. There were tendencies for the progesterone concentrations of the weaned group on days $7(\mathrm{P}=0.07)$ and 25 $(\mathrm{P}=0.06)$ to be higher than those of the suckled group. There was no difference in the estradiol- $17 \beta$ profile between the weaned and suckled groups. 

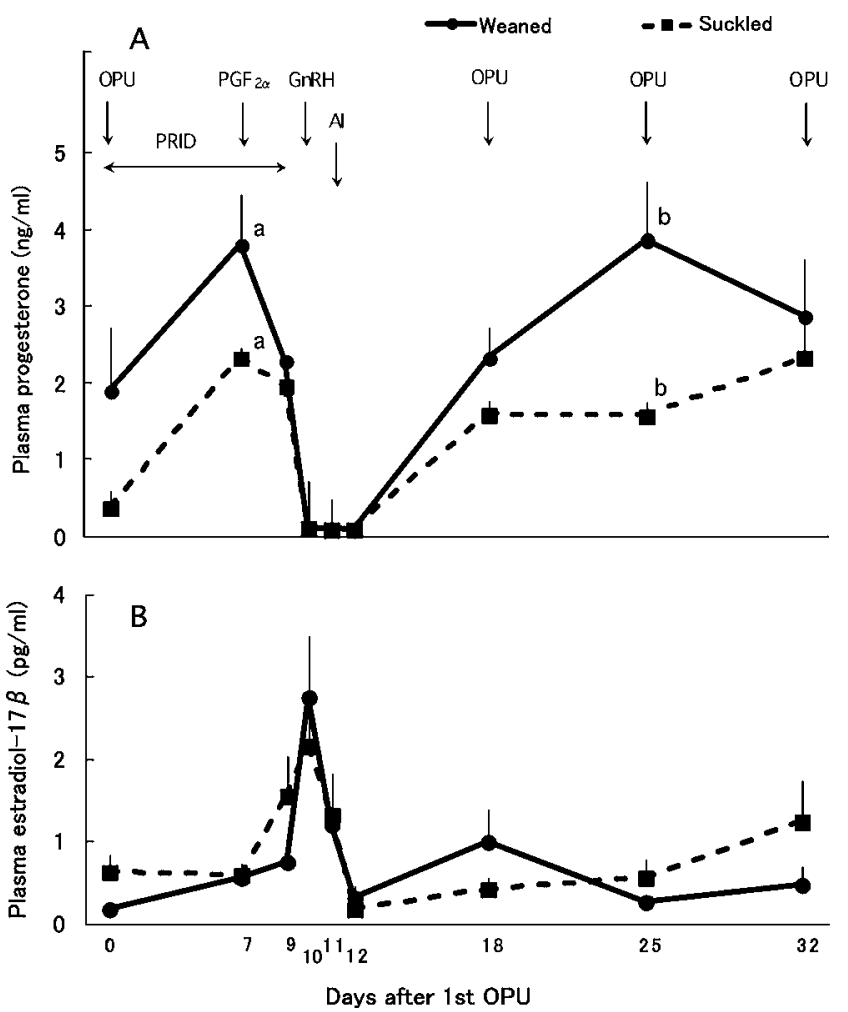

Fig. 1. Profiles of the plasma progesterone (A) and estradiol-17 $\beta$ (B) concentrations (mean \pm SEM) of the early postpartum Japanese Black cows treated with the OPU-PRID-TAI protocol in the weaned $(n=7)$ and suckled groups $(n=7)$. A significant difference $(\mathrm{P}=0.03)$ was found in the progesterone profile. No significant difference was found in the estradiol- $17 \beta$ profile. $\mathrm{P}=0.07$ for a and $\mathrm{P}=0.06$ for $\mathrm{b}$ for comparisons between the groups at the same time points. OPU: Ovum pick-up. PRID: placement of a progesterone-releasing intravaginal device for 9 days. $\mathrm{PGF}_{2 \alpha}$ : intramuscular injection of $500 \mu \mathrm{g}$ of cloprostenol, a prostaglandin $\mathrm{F}_{2 \alpha}$ analog. GnRH: intramuscular injection of 100 $\mu \mathrm{g}$ of fertirelin acetate, a GnRH analog. AI: artificial insemination.

The profiles of both progesterone and estradiol- $17 \beta$ did not differ between the subsequent pregnant and non-pregnant groups.

\section{Discussion}

The OPU-PRID-TAI protocol documented here can be used as a management tool to improve the reproductive performance and effectiveness of OPU before and after TAI in early postpartum suckled and weaned beef cows. We have shown that early postpartum beef cows (around 30 days postpartum) respond to this TAI protocol with a high conception rate. A high number of oocytes can be collected both before and after insemination, especially in weaned animals. Our results suggest that the OPU-PRID- TAI protocol is applicable to early postpartum beef cows and that successive OPU sessions during early pregnancy in animals bred by TAI does not impair maintenance of pregnancy. We also demonstrated a high conception rate in suckled early postpartum cows treated with a similar OPU-PRID- TAI protocol in our previous study [14]. In the present study, we used a protocol in which a PRID was inserted for 9 days, PGF $_{2 \alpha}$ was administered two days before PRID removal and GnRH was administered 36 hours after PRID removal to minimize the risk of ovulation before GnRH administration. The applicability of the 36-h interval between CIDR removal and GnRH in a timed AI protocol for beef cattle has been demonstrated previously [17]. This protocol is designed such that the plasma estradiol- $17 \beta$ concentration at the time of $\mathrm{GnRH}$ injection in the cow is as high as that in the cow at estrous. However, the average value in this study was lower than that reported previously [18]. This result suggests that the 36-h interval between PRID removal and GnRH applied in this study was rather short and so the ovulatory follicle had not matured sufficiently by the time of GnRH injection.

The numbers of oocytes collected and blastocysts generated were similar among the four OPU sessions in the weaned and suckled groups. This result suggests that repeated OPU at intervals of 7 days in early pregnancy is applicable in producing a certain number of transferable embryos. However, an interval of 7 days between OPU sessions may not be optimal for production of the maximum number of embryos by repeated OPU because it may allow development of a dominant follicle that exerts a deleterious influence on oocytes from subordinate follicles [13]. It has been suggested that repeated OPU twice a week can lead to maximum production of culture-competent oocytes because performance of follicle aspiration frequently enough to induce a newly recruited cohort of follicles and to prevent development of a dominant follicle yields a higher number of harvestable follicles and oocytes [5, 13, 19-21]. Oocyte collection by OPU from pregnant cows is often reported, and this procedure has not been shown to cause pregnancy loss [9$11,22]$. It is well known that repeated OPU at short intervals is possible [10, 19, 23]. Ooe et al. [12] demonstrated that repeated OPU at 5-day intervals in conjunction with FSH treatment in cows that are 70 to 100 days pregnant is effective. Our results indicate that oocyte collection by three successive OPU sessions at 7-day intervals from cows that are 7 to 21 days pregnant is possible and not harmful to pregnancy. Conversely, no difference in OPU outcome was found between the subsequent pregnant and nonpregnant cows. Although a 7-day interval between the OPU sessions was chosen in this study for practical reasons to allow for farm visits on a constant day of the week, further research is necessary to clarify whether the effect of repeated OPU once a week is beneficial to embryo production without risking pregnancy in cows at a very early stage of pregnancy.

The total numbers of oocytes collected, cultured oocytes, cleavage embryos, blastocysts generated on day 7 and blastocysts on days 7-9 of the four OPU sessions were significantly higher in the weaned group compared with the suckled group. In addition, the proportions of cleavage embryos, blastocysts on day 7 and blastocysts on days 7-9 to cultured oocytes in the weaned group were significantly higher than those in the suckled group. These results indicate that oocytes collected from weaned cows may be superior not only in quantity, but also in quality compared with those collected from suckled cows. The reasons why the weaned cows had better OPU results may be explained by the fact that more of the 
animals had resumed postpartum ovarian function and, therefore, had already commenced normal growth of a small follicle cohort. Ovarian cyclicity resumes around 14 to 21 days postpartum in weaned cows in contrast to 21 to 28 days postpartum in suckled cows [24]. It has also been shown that suckling delays postpartum ovarian resumption in Japanese Black cows [25]. Another explanation for why more culture-competent oocytes were collected in the weaned group might be that normal growth of follicles and oocytes requires normal gonadotropin secretion and that gonadotropin secretion is inhibited in early postpartum suckled beef cows [2629]. Since normal follicular and oocyte growth is probably necessary for normal development of blastocysts in vitro, the effects of suckling on the plasma FSH and LH profiles and follicular profiles (number and size) around the time of OPU in Japanese Black cows should be clarified in future research.

The average numbers ( \pm SD) of blastocysts produced from one session of OPU-IVP were $3.5 \pm 4.0$ and $1.3 \pm 1.8$ in the weaned and suckled groups, respectively. The market value of a transferable embryo at the blastocyst stage from a superior Japanese Black donor is more than 300 US dollars. Therefore, the difference between 3.5 and 1.3 embryos was not only statistically significant, but was also practically significant, particularly in the case of Japanese Black cows.

The average plasma progesterone concentrations 14 days after TAI in the suckled group tended to be lower than those in weaned group. This result was attributable to the animals in the suckled group either forming a subfunctional CL resulting in a decreased progesterone level after 7 days post AI or experiencing delayed luteinization after induced ovulation, in addition to the one animal that did not ovulate as a result of GnRH injection. The suckling stimulus intervenes in GnRH release from the hypothalamus and inhibits pulsatile LH release in suckled cows [1, 29, 30]. Therefore, our results indicate that inhibition of pulsatile secretion of $\mathrm{LH}$ may have caused suboptimal or delayed luteinization in the cows treated with the OPU-PRID-TAI protocol. It has been reported that calf removal for $48 \mathrm{~h}$, from the time of $\mathrm{PGF}_{2 \alpha}$ administration on day 7 to the time of the second GnRH dose on day 9 in the Ovsynch or Co-synch protocols, improves conception rates in both cycling and anestrous beef cows [31]. Even though further investigation is required concerning the effects of suckling on follicular growth, luteal function after induction of ovulation and the in vitro developmental ability of oocytes collected via OPU, removal of calves from their dams for $48 \mathrm{~h}$ appears to be effective when conducting a TAI protocol in early postpartum beef cows.

In conclusion, our results suggest that it is possible to produce a number of high quality embryos in vitro by repeated OPU and IVP following the OPU-PRID-TAI protocol in early postpartum Japanese Black cows. We expect to collect more oocytes and produce more embryos if calves are removed from cows scheduled to be treated using the OPU-PRID-TAI protocol.

\section{Acknowledgements}

We are grateful to Dr. Niswender GD (Colorado State University, Fort Collins, CO, USA) for providing the steroid hormone antisera. This research was supported in part by a Grant-in-Aid for
Scientific Research (No. 19580367) to T. O. from the Japan Society for the Promotion of Science.

\section{References}

1. Yavas Y, Walton JS. Postpartum acyclicity in suckled beef cows. Theriogenology 2000; 54: 25-55.

2. Fike KE, Day ML, Inskeep EK, Kinder JE, Lewis PE, Short RE, Hafs HD. Estrus and luteal function in suckled beef cows that were anestrous when treated with an intravaginal device containing progesterone with or without a subsequent injection of estradiol benzoate. J Anim Sci 1997; 75: 2009-2015.

3. Peters AR. Calving intervals of beef cows treated with either gonadotrophin releasing hormone or a progesterone releasing intravaginal device. Vet Rec 1982; 110: 515-517.

4. López-Gatius F, Santolaria P, Yániz J, Rutlant J, López-Béjar M. Persistent ovarian follicles in dairy cows: a therapeutic approach. Theriogenology 2001; 56: 649-659.

5. Galli C, Crotti G, Notari C, Turini P, Duchi R, Lazzari G. Embryo production by ovum pick up from live donors. Theriogenology 2001; 55; 1341-1357.

6. Pieterse MC, Kapen KA, Kruip THAM, Taverne MAM. Aspiration of bovine oocytes during transvaginal ultrasound scanning of the ovaries. Theriogenology 1988; 30: 751762.

7. Van der Schans A, Van der Westerlaken LAJ, de Wit AAC, Eyestone WH, de Boer HA. Ultrasound-guided transvaginal collection of oocytes in the cow. Theriogenology 1991; 35: 288.

8. Van Wagtendonk-de Leeuw AM. Ovum Pick Up and In Vitro Production in the bovine after use in several generations: A 2005 status. Theriogenology 2006; 65: 914-925.

9. Ryan DP, Blakewood EG, Swanson WF, Rodriguez H, Godke RA. Using hormonetreated pregnant cows as a potential source of oocytes for in vitro fertilization. Theriogenology 1993; 40: 1039-1055.

10. Bungartz L, Lucas-Hahn A, Rath D, Niemann H. Collection of oocytes from cattle via follicular aspiration aided by ultrasound with or without gonadotropin pretreatment and in different reproductive stages. Theriogenology 1995; 43: 667-675.

11. Meintjes M, Bellow MS, Broussard JR, Paul JB, Godke RA. Transvaginal aspiration of oocytes from hormone-treated pregnant beef cattle for in vitro fertilization. J Anim Sci 1995; 73: 967-974.

12. Ooe M, Rajamahendran R, Boediono A, Suzuki T. Ultrasound-guided follicle aspiration and IVF in dairy cows treated with FSH after removal of the dominant follicle at different stages of the estrous cycle. J Vet Med Sci 1997; 59: 371-376.

13. Chaubal SA, Molina JA, Ohlrichs CL, Ferre LB, Faber DC, Bols PEJ, Riesen JW, Tian $\mathrm{X}$, Yang $\mathrm{X}$. Comparison of different transvaginal ovum pick-up protocols to optimize oocyte retrieval and embryo production over a 10-week period in cows. Theriogenology 2006; 65: 1631-1648.

14. Hirata TI, Hoshina T, Sasaki SI, Sasaki O, Osawa T. Applicability of a progesteronebased timed AI protocol after follicular fluid aspiration using the ovum pick-up technique in suckled beef cows. J Reprod Dev 2007; 53: 171-177.

15. Taya K, Watanabe $\mathrm{G}$, Sasamoto $\mathrm{S}$. Radioimmunoassay for progesterone, testosterone and estradiol-17 $\beta$ using ${ }^{125}$ I-iodohistamine radioligands. Jpn J Anim Reprod 1985; 31 186-197.

16. Yamashita S, Abe H, Itoh T, Satoh T, Hoshi T. A serum-free culture system for efficient in vitro production of bovine blastocysts with improved viability after freezing and thawing. Cytotechnology 1999; 31: 121-129.

17. Kasimanickam R, Collins JC, Wuenschell J, Currin JC, Hall JB, Whittier DW. Effect of timing of prostaglandin administration, controlled internal drug release removal and gonadotropin releasing hormone administration on pregnancy rate in fixed-time AI protocols in crossbred Angus cows. Theriogenology 2006; 66: 166-172.

18. Osawa T, Morishige D, Ohta D, Kimura Y, Hirata T-I, Miyake Y-I. Comparison of the effectiveness of ovulation synchronization protocol in anestrous and cycling beef cows. J Reprod Dev 2003; 49: 513-521.

19. Gibbons JR, Beal WE, Krisher RL, Faber EG, Pearson RE, Gwazdauskas FC. Effects of once- versus twice-weekly transvaginal follicular aspiration on bovine oocyte recovery and embryo development. Theriogenology 1994; 42: 405-419.

20. Goodhand KL, Watt RG, Stains ME, Hutchinson JSM, Broadbent PJ. In vivo oocyte recovery and in vitro embryo production from bovine donors aspirated at different frequencies or following FSH treatment. Theriogenology 1999; 51: 951-961.

21. Merton JS, de Roos APW, Mullaart E, Ruigh LD, Kaal L, Vos PLAM, Dieleman SJ Factors affecting oocyte quality and quantity in commercial application of embryo technologies in the cattle breeding industry. Theriogenology 2003; 59: 651-674.

22. Hirata T, Sasaki S, Sasaki O, Osawa T. Successive ovum pick-up followed by in vitro embryo production (OPU-IVP) during pregnant periods in Japanese Black cattle. Jpn J Embryo Transf 2005; 27: 78-86.

23. Garcia A, Salaheddine M. Effects of repeated ultrasound-guided transvaginal follicular aspiration on bovine oocytes recovery and subsequent follicular development. The 
riogenology 1998; 50: 575-585

24. Williams GL. Suckling as a regulator of postpartum rebreeding in cattle. J Anim Sci 1990; 68: 831-852.

25. Kawashima C, Kida K, Matsuhashi M, Matsui M, Shimizu T, Matsunaga N, Ishii M, Miyake Y, Miyamoto A. Effect of suckling on the reproductive performance and metabolic status of obese Japanese Black cattle during the early postpartum period. J Reprod Dev 2008; 54: 46-51.

26. Hendriksen PJ, Vos PL, Steenweg WN, Bevers MM, Dieleman SJ. Bovine follicular development and its effect on the in vitro competence of oocytes. Theriogenology 2000; 53: 11-20.

27. Kawate N, Yamazaki M, Tamada H, Inaba T, Sawada T. Effect of low dose of hCG on induction of fertile estrus in shiba goats pretreated intravaginally with progesterone during the early postpartum nursing period. J Reprod Dev 2002; 48: 497-504.

28. Walters DL, Kaltenbach CC, Dunn TG, Short RE. Pituitary and ovarian function in postpartum beef cows. I. Effect of suckling on serum and follicular fluid hormones and follicular gonadotropin receptors. Biol Reprod 1982; 26: 640-646.

29. Williams GL, Gazal OS, Guzman Vega GA, Stanko RL. Mechanisms regulating suckling-mediated anovulation in the cow. Anim Reprod Sci 1996; 42: 289-297.

30. Montiel F, Ahuja C. Body condition and suckling as factors influencing the duration of postpartum anestrus in cattle. Anim Reprod Sci 2005; 85: 1-26.

31. Geary TW, Whittier JC, Hallford DM, MacNeil MD. Calf removal improves conception rates to the Ovsynch and CO-Synch protocols. J Anim Sci 2001; 79: 1-4. 